\title{
Stability Improvement of Distributed Power Generation Systems with an LCL-Filter Using Gain Scheduling Based on Grid Impedance Estimations
}

\author{
Dae-Keun Choi* and Kyo-Beum Lee ${ }^{\dagger}$ \\ ${ }^{\dagger *}$ School of Electrical and Computer Engineering, Ajou University, Suwon, Korea
}

\begin{abstract}
This paper proposes a gain scheduling method that improves the stability of grid-connected systems employing an LCL-filter. The method adjusts the current controller gain through an estimation of the grid impedance in order to reduce the resonance that occurs when using an LCL-filter to reduce switching harmonics. An LCL-filter typically has a frequency spectrum with a resonance peak. A change of the grid-impedance results in a change to the resonant frequency. Therefore an LCL-filter needs a damping method that is applicable when changing the grid impedance for stable system control. The proposed method instantaneously estimates the grid impedance and observes the resonant frequency at the same time. Consequently, the proposed method adjusts the current controller gain using a gain scheduling method in order to guarantee current controller stability when a change in the resonant frequency occurs. The effectiveness of the proposed method has been verified by simulations and experimental results.
\end{abstract}

Key Words: Active damping, Distributed power generation, Grid-connected system, Grid impedance estimation, LCL-filter

\section{INTRODUCTION}

As the importance of renewable energy increases and relevant technologies develop, the use of distributed power generation systems (DPGSs), such as photovoltaic systems or wind turbine systems, has increased. In such systems, the power conversion devices make up a very important part and are being continuously developed [1]-[7]. However, the harmonics caused by a low switching frequency during power conversion can make these systems instable [8]. To attenuate the effects of these harmonics, inductance filters (L-filters) are connected to both sides of the power conversion device. As the capacity of a system increases, the inductance of the Lfilter increases as well. Such an increase in the inductance may cause a rise in the manufacturing costs or undesirable dynamic response characteristics. The large inductance of an L-filter can be reduced by employing an LCL-filter [9]. An LCL-filter requires a smaller inductance than a $\mathrm{L}$-filter used alone to effectively reduce the switching harmonics. This allows the manufacturing cost of the system to be reduced. However, when the filter parameters are not properly chosen, it is not possible to achieve an effective reduction in the harmonics and the additional poles needed by the added LC part can cause further resonance and, hence, system instability [10], [11]. One possible solution to this problem is to use a passive

\footnotetext{
Manuscript received Sep. 9, 2010; revised May 17, 2011

Recommended for publication by Associate Editor Nam-Sup Choi.

$\dagger$ Corresponding Author: kyl@ajou.ac.kr

Tel: +82-31-219-2376, Fax: +82-31-212-9531, Ajou University

* School of Electrical and Comp. Eng., Ajou University, Korea
}

damping method that can solve the resonance phenomenon by simply adding a resistance to the capacitor terminal of the LCL-filter. This method is applicable to small capacity systems, but as the capacity grows, the efficiency goes down due to the additional damping resistance and it requires an additional heat sink. Therefore, active damping is used in large capacity systems. Conventional active damping methods use a lead-leg compensator, which is a difficult method for selecting the time constant needed for damping [12], [13]. Moreover, the methods that use a virtual resistance or a multi roof controller have to add a current sensor to the capacitor leg [14]. However, even after the system is stabilized, the grid impedance may change. This, in turn, will cause a reduction in the bandwidth of the controller. If a mainly inductive variation of the grid impedance occurs in the grid, the bandwidth of the controller decreases and the filter will not fulfill its initial design purpose [15], [16]. It is necessary that an active damping method be used when the grid impedance changes, in order to achieve stable control of the system. The proposed active damping method, when compared to conventional methods, makes it easy to determine the controller parameters, simplifies the calculation algorithm, and does not require an additional sensor. Moreover, it is possible to actively control it for changing the impedances when it is grid connected.

The objective of this paper is to improve the stability of DPGSs with an LCL-filter by employing a gain scheduling method that uses grid impedance estimation. The validity of the proposed method is proven by simulations and experimental results. 


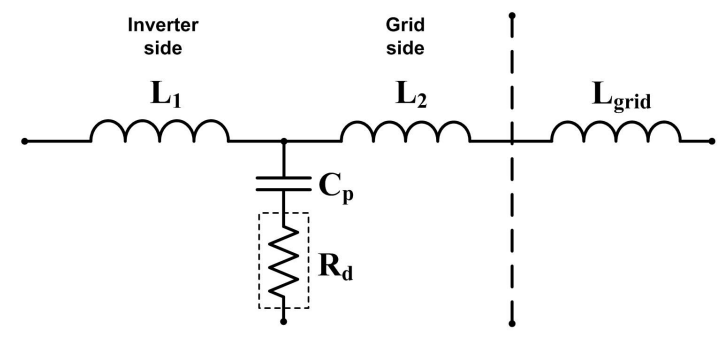

Fig. 1. The equivalent circuit of the LCL-filter.

\section{THE LCL-FILTER}

The use of an LCL-filter in grid-connected systems is a general and widely used practice that is also found in industrial products. LCL-filters offer the possibility of reducing the harmonics caused by the switching of the power conversion system with reduced inductance values, when compared to L-filters. An LCL-filter is comprised of two inductors and a capacitor connected in parallel, as shown in Fig. 1. According to the effects that the parameters have on the system, each parameter is designed using various standard procedures [9].

\section{A. LCL-Filter Modeling}

The designed LCL-filter can be expressed as a single phase equivalent circuit, as shown in Fig. 1. The transfer function is presented in (1). $\mathrm{L}_{1}$ is the inductance of the inverter-side inductor, $\mathrm{L}_{2}$ is the inductance of the grid-side inductor, and $\mathrm{L}_{\text {grid }}$ is the inductance of the grid. $\mathrm{C}_{\mathrm{p}}$ is the capacitance of the parallel capacitor of the LCL-filter and $\mathrm{R}_{\mathrm{d}}$ is the resistor used for passive damping. If a damping resistor is not used for the resonance compensation, then (1) can be represented as (2).

$$
G(s)=\frac{i(s)}{v(s)}=\frac{1}{L s} \frac{\left(s^{2}+R_{d} C_{f} z_{L C}^{2} s+z_{L C}^{2}\right)}{\left(s^{2}+R_{d} C_{f} \omega_{r e s}^{2} s+\omega_{r e s}^{2}\right)} .
$$

where, $z_{L C}^{2}=\frac{1}{L_{T} C_{f}}, \omega_{\text {res }}^{2}=\frac{L_{T} z_{L C}^{2}}{L}, L_{T}=L_{g}\left(=L_{2}+L_{\text {grid }}\right)+L$

$$
G(s)=\frac{i(s)}{v(s)}=\frac{1}{L s} \frac{\left(s^{2}+z_{L C}^{2}\right)}{\left(s^{2}+\omega_{r e s}^{2}\right)} .
$$

\section{B. LCL-Filter Design}

The designing process for each of the LCL-filter's parameters is as follows:

1) Calculate the base impedance value:

$$
M_{i}=\frac{\sqrt{2} E_{n}}{V_{d c} / 2}, L_{b}=\frac{1}{2 \pi f_{n}} \frac{E_{n}^{2}}{P}, C_{b}=\frac{P}{2 \pi f_{n} E_{n}^{2}} .
$$

where $M_{i}$ is the modulation index, $E_{n}$ is the line voltage root mean square value, $f_{n}$ is the fundamental frequency, and $P$ is the rated power.

2) Select the inverter side inductor's inductance value:

Because the inverter side inductance is determined by the converter side ripple rate of the LCL-filter, the inner inductance must be designed precisely in order to reduce the trial and error in the filter design.

$$
L_{i}=\frac{L_{b}}{R F_{1}} \frac{f_{n}}{f_{s w}} \sqrt{\frac{\pi^{2}}{16} M_{i}^{2}-\frac{4 \pi}{9} M_{i}+\frac{\pi^{2}}{12}} .
$$

where $R F_{1}$ is the ripple rate of the switching frequency band and $f_{s w}$ is the switching frequency.

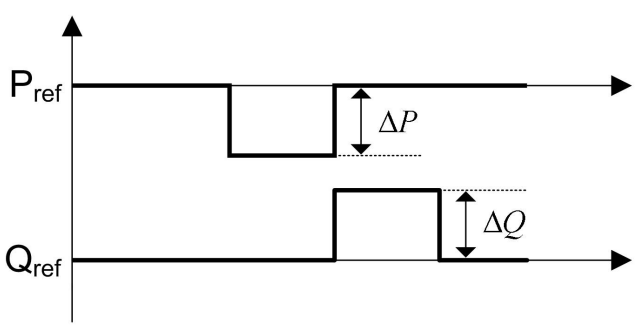

(a)

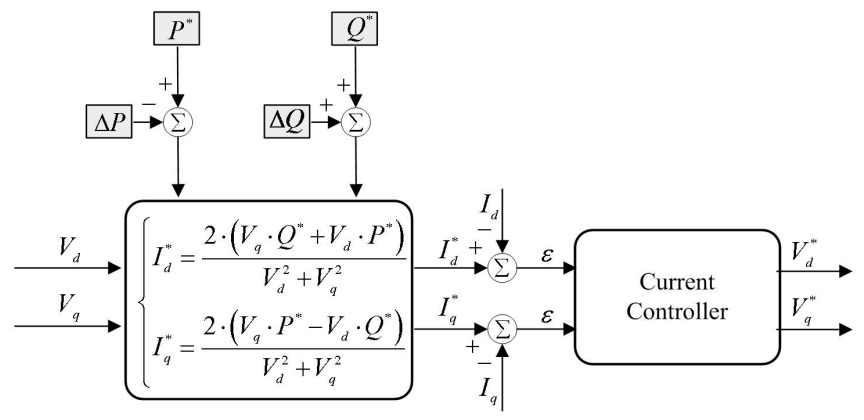

(b)

Fig. 2. The control block diagram for the grid impedance estimation.

3) Select the capacitor value: The value of the capacitor is calculated through a percentage of the reactive power absorbed under rated conditions.

$$
C_{p}=x C_{b} .
$$

where $x$ is the reactive power rate absorbed in the capacitor.

4) Select the grid side inductor's inductance value: The inductance rate $(r)$ is determined through the relationship between the outer current ripple and the inner current ripple. The relation between the outer inductance and the inner inductance can also be determined by using the inductance rate.

$$
\begin{gathered}
a=\frac{R F_{1}}{R F_{2}}, b=x L_{1} C_{b} \omega_{s w}^{2} . \\
r=\left|\frac{1 / a+1}{1-b}\right| . \\
L_{g}=r L_{1} .
\end{gathered}
$$

where $R F_{2}$ is the current ripple rate.

5) Select the passive damping resistance value:: The damping resistance's need to remove the resonance is equal to one third of the impedance of the capacitor in the resonant frequency.

$$
\begin{gathered}
f_{\text {res }}=\frac{1}{2 \pi} \sqrt{\frac{L_{1}+L_{g}}{L_{1} L_{g} C_{f}}} . \\
R_{d}=\frac{1}{6 \pi f_{r e s} C_{f}} .
\end{gathered}
$$

where $f_{\text {res }}$ is the resonant frequency. 


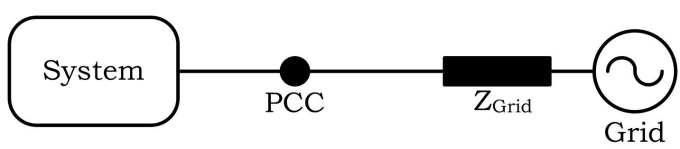

Fig. 3. The PCC (Point of Common Coupler).

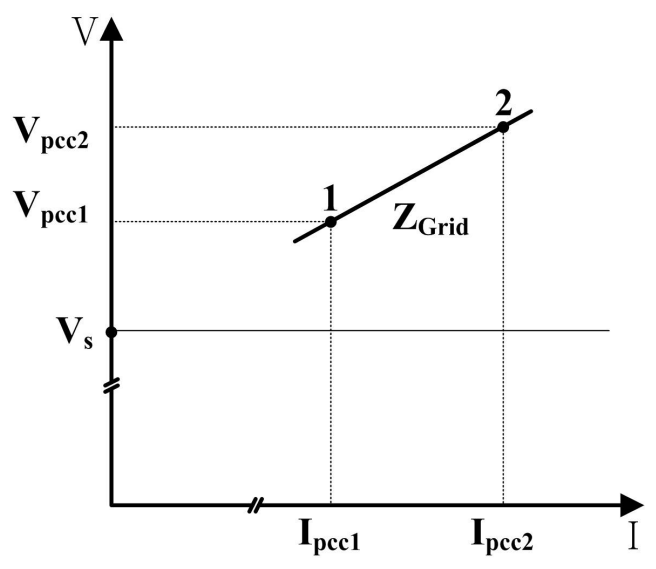

Fig. 4. The power converter working at two operation points.

\section{The Proposed Gain Scheduling Method}

A variation in the grid impedance causes a change to the resonance frequency determined by the LCL-filter design. This causes an unintended stability problem. In this paper, the stability of a system is guaranteed by setting up a proper controller gain compliant to the changes in the inductance by estimating the grid impedance.

\section{A. Grid Impedance Estimation}

This method is based on the production of a small perturbation on the output of the grid-connected inverter that is in the form of periodical variations in active and reactive power (PQ variations) [16]. The principle of the variation of active and reactive power is presented in Fig. 2.

A PQ control strategy is required in order to implement this method for grid-connected systems, as presented in [17]. The method for estimating the grid impedance used in this paper is by changing the active power and the reactive power that occur in the system. In order to estimate the grid impedance, the system requires a controller that can change the reactive power and active power references, as seen in Fig. 2. $\Delta_{P}$ indicates the amount of active power variation and $\Delta_{Q}$ indicates the amount of reactive power variation. The accuracy of this method depends on the PQ variation values and the duration of the perturbation. The PQ control principle is based on the relations presented in (3) and (4) according to [14].

$$
\begin{gathered}
P=\frac{1}{2}\left(V_{d} \cdot I_{d}+V_{q} \cdot I_{q}\right) . \\
Q=\frac{1}{2}\left(V_{q} \cdot I_{d}-V_{d} \cdot I_{q}\right) \\
I_{d}^{*}=\frac{2 \cdot\left(V_{q} \cdot Q^{*}+V_{d} \cdot P^{*}\right)}{V_{d}^{2}+V_{q}^{2}} \\
I_{q}^{*}=\frac{2 \cdot\left(V_{q} \cdot P^{*}+V_{d} \cdot Q^{*}\right)}{V_{d}^{2}+V_{q}^{2}} .
\end{gathered}
$$

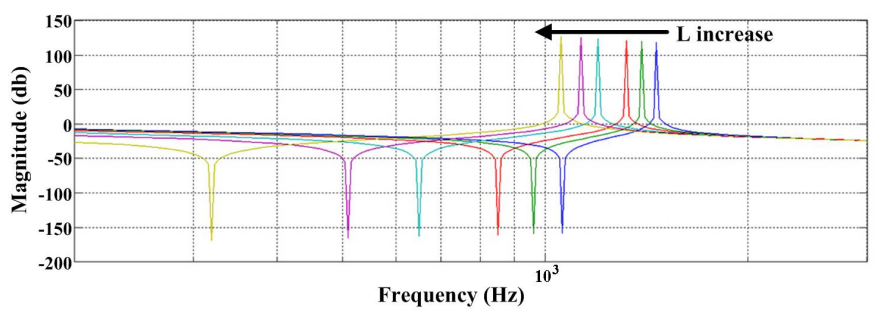

Fig. 5. The Bode plot of a system for different values of the grid inductance $\mathrm{L}$ in an LCL-filter.

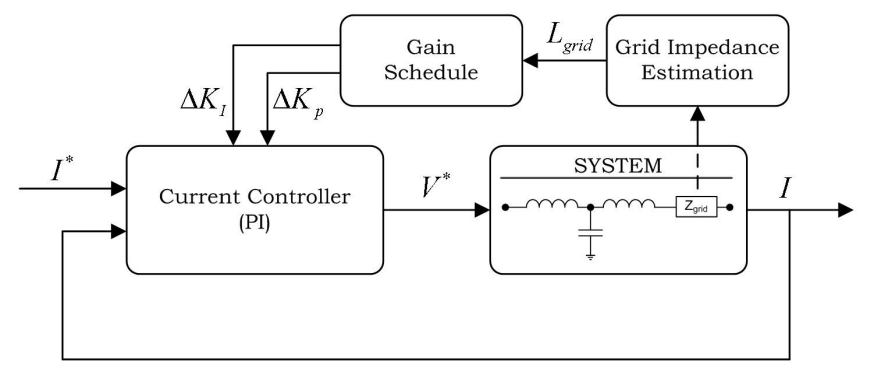

Fig. 6. The gain scheduling method.

Fig. 3 shows the PCC (Point of Common Coupler) at which the current and voltage for estimating the grid impedance are measured. Fig. 4 is a graph that shows the algorithm for estimating the grid impedance in a system that has adopted the PQ variations. $Z_{\text {Grid }}$ is the grid impedance and $V_{s}$ is the grid voltage. The grid voltage and the current variations are necessary in order to estimate the impedance value:

$$
\bar{Z}_{\text {Grid }}=\frac{\Delta \bar{V}_{P C C}}{\Delta \bar{I}_{P C C}} .
$$

This is convenient for power generation systems based on renewable energy, such as wind or photovoltaic systems, which have a variable input power. Considering that the variations in the input power are reflected into the power delivered to the utility grid, these variations can be used to derive the necessary voltages and currents under two different operating conditions, as in Fig. 4. In (6), which shows the voltage relations at the PCC, $Z_{\text {Grid }}$ is the grid impedance and $V_{s}$ is the grid voltage. Because $V_{s}$ cannot be measured, estimation of the grid impedance using (6) is difficult. Therefore, the idea is to make the power converter work at two operation points, as presented in Fig. 4, in order to remove the unknown variable $V_{s}$ from (6). By subtracting (7) from (6), $V_{s}$ is avoided, as can be seen in (8).

$$
\begin{gathered}
\bar{V}_{P C C 1}=\bar{I}_{P C C 2} \cdot \bar{Z}_{G r i d}+\bar{V}_{s} . \\
\bar{V}_{P C C 2}=\bar{I}_{P C C 2} \cdot \bar{Z}_{G r i d}+\bar{V}_{s} . \\
\bar{V}_{P C C 1}-\bar{V}_{P C C 2}=\bar{Z}_{G r i d}\left(\bar{I}_{P C C 1}-\bar{I}_{P C C 2}\right) .
\end{gathered}
$$

Equation (9) shows the relationships between the grid impedance, the current, and the voltage measured at the PCC. As a result, (10) shows the $R$ and $L$ of the grid impedance that are desired to estimate. For the estimation of the actual grid impedance, the $d q$-axis current and voltage values are used, as seen in (11).

$$
\bar{Z}_{\text {Grid }}=\bar{R}+j \cdot \omega \bar{L}=\frac{\bar{V}_{P C C 1}-\bar{V}_{P C C 2}}{\bar{I}_{P C C 1}-\bar{I}_{P C C 2}} .
$$




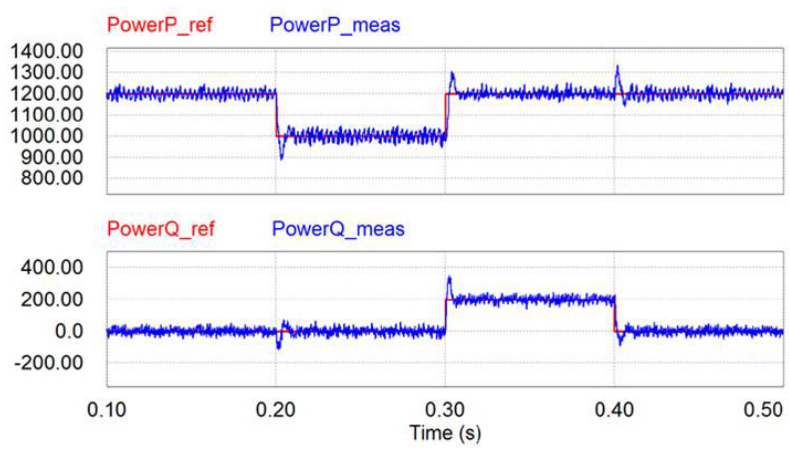

Fig. 7. The variations in the active (upper) and reactive (lower) power.

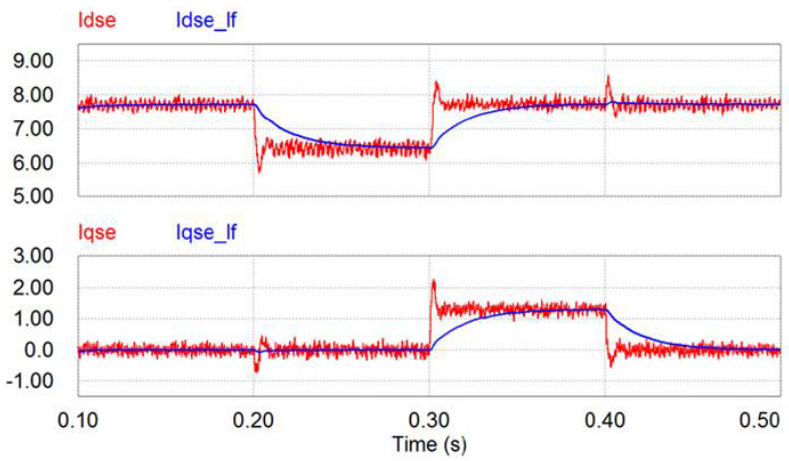

Fig. 8. The d-axis (upper) and q-axis (lower) current.

$$
\begin{gathered}
R=\operatorname{Re}\left(\frac{\bar{V}_{P C C 1}-\bar{V}_{P C C 2}}{\bar{I}_{P C C 1}-\bar{I}_{P C C 2}}\right) \\
L=\frac{1}{\omega} \cdot \operatorname{Im}\left(\frac{\bar{V}_{P C C 1}-\bar{V}_{P C C 2}}{\bar{I}_{P C C 1}-\bar{I}_{P C C 2}}\right) \\
R=\frac{\Delta V_{d} \cdot \Delta I_{d}+\Delta V_{q} \cdot \Delta I_{q}}{\Delta I_{d}^{2}+\Delta I_{q}^{2}} \\
L=\frac{\Delta V_{q} \cdot \Delta I_{d}-\Delta V_{d} \cdot \Delta I_{q}}{\left(\Delta I_{d}^{2}+\Delta I_{q}^{2}\right) \cdot \omega}
\end{gathered}
$$

\section{B. Resonance Frequency Characteristics of the LCL-Filter}

The change of the grid impedance, seen in (12), changes the system inductance. A change of the impedance in the grid $\left(L_{\text {grid }}\right)$ will affect the overall inductance of the grid-side of the system $\left(L_{g}\right)$ as in:

$$
L_{g}=L_{2}+L_{\text {grid }} .
$$

Such a change of $L_{g}$ also causes a variation in the resonance frequency according to:

$$
\omega_{\text {res }}=\sqrt{\frac{L_{T}}{L_{1} L_{g} C_{f}}} .
$$

This change of the resonance frequency, in turn, affects the stability of the overall system regarding the cut-off frequency of the controller. Fig. 5 shows the change of the resonance frequency according to variations in the grid inductance.

\section{Gain Scheduling Using Grid Impedance Estimation}

The grid impedance also has an impact on the control of the grid inverters. Large variations of the grid impedance highly decreases the stability and performance of the current

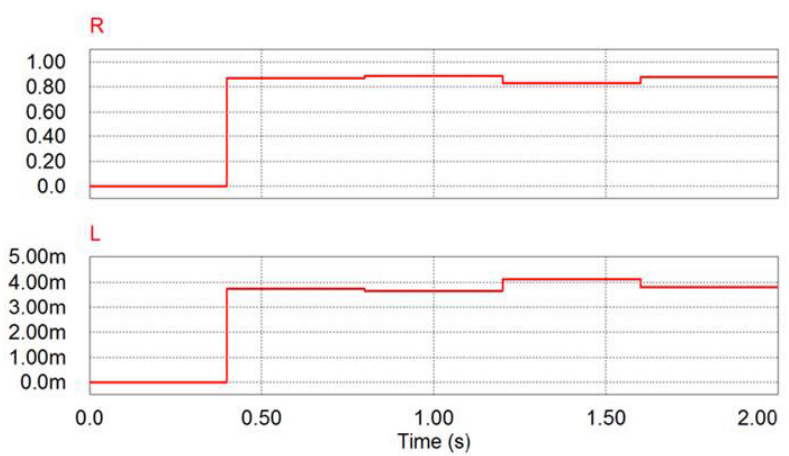

Fig. 9. The estimated grid impedance $\mathrm{R}=1 \Omega, \mathrm{L}=4 \mathrm{mH}$.

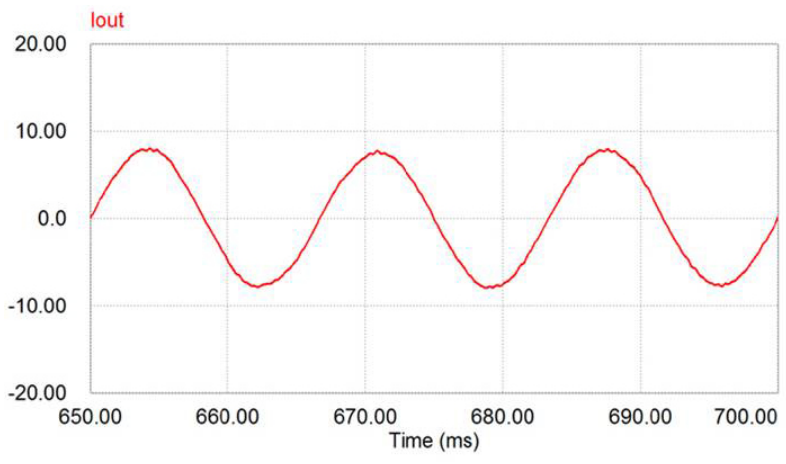

(a) Grid inductance $=3 \mathrm{mH}, \mathrm{K}_{\mathrm{p}}=36, \mathrm{~K}_{\mathrm{I}}=350$.

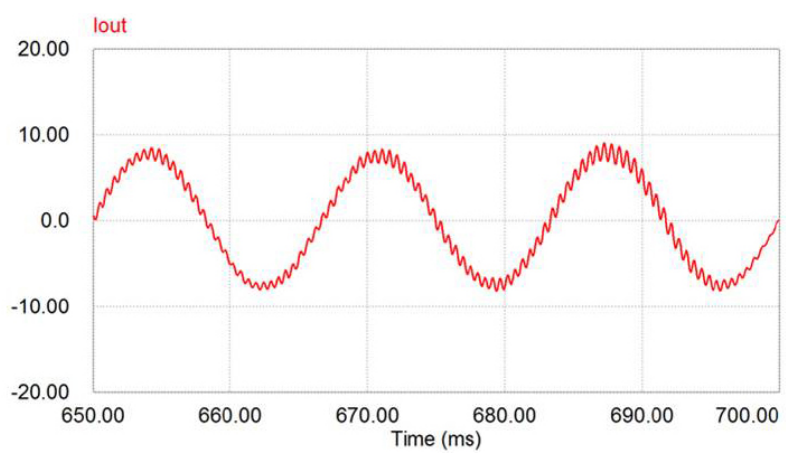

(b) Grid inductance $=4 \mathrm{mH}, \mathrm{K}_{\mathrm{p}}=36, \mathrm{~K}_{\mathrm{I}}=350$.

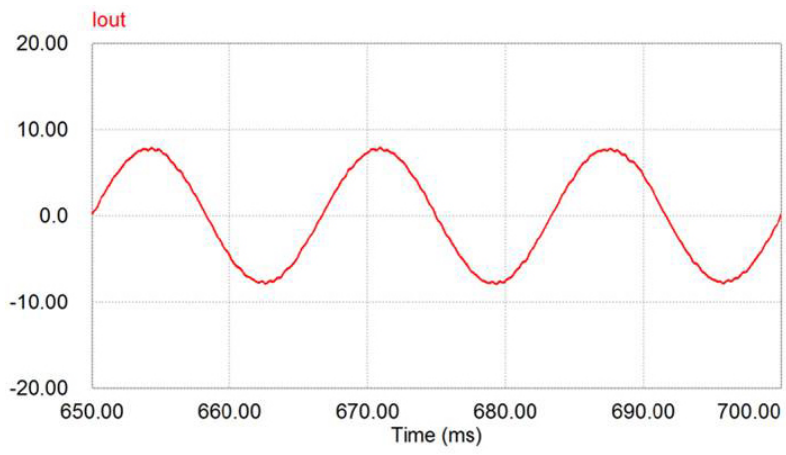

(c) Grid inductance $=4 \mathrm{mH}, \mathrm{K}_{\mathrm{p}}=24, \mathrm{~K}_{\mathrm{I}}=270$.

Fig. 10. The output current waveforms of the grid-connected inverter 


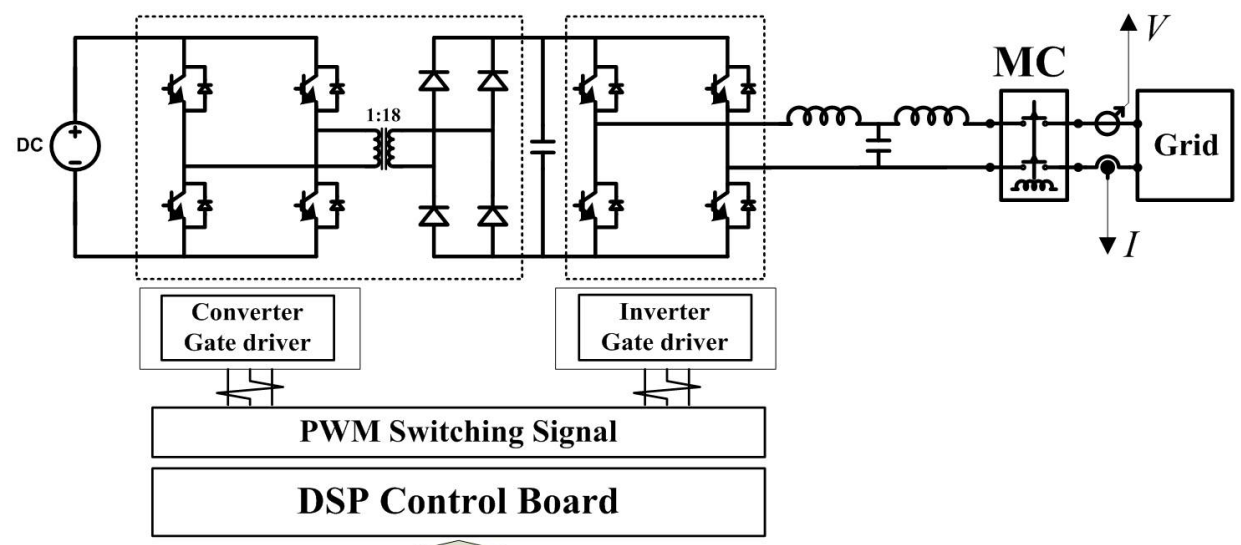

A/D Input

Fig. 11. The schematic diagram of the experimental setup.

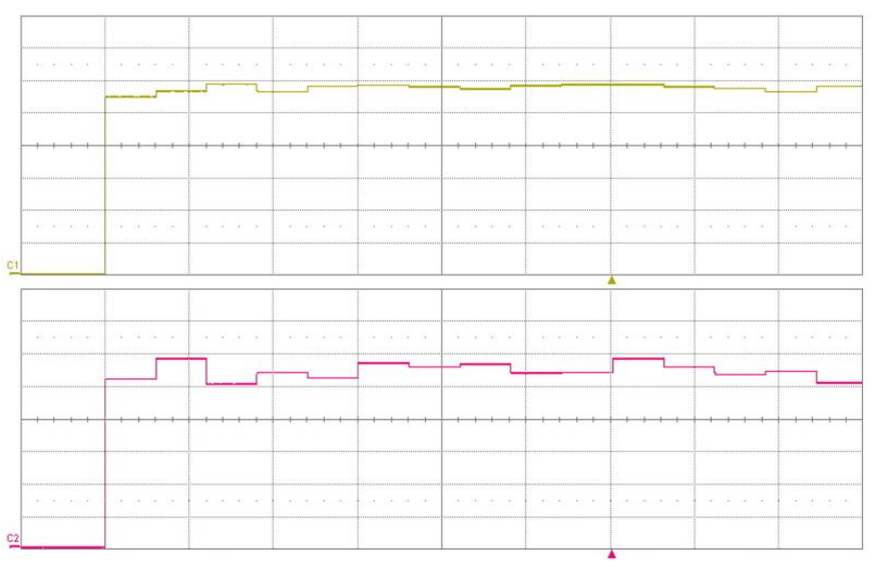

Fig. 12. The estimated grid impedance. L (upper) (x-axis: 5s/div., y-axis: $500 \mathrm{uH} / \mathrm{div}) \mathrm{R}$ (lower) (x-axis: $5 \mathrm{~s} / \mathrm{div}$., y-axis: $35 \mathrm{~m} \Omega / \mathrm{div})$.

controller. The performance of the inverter also depends on the grid impedance and the grid voltage which, in most cases, is distorted due to other nonlinear loads connected to the PCC. The parameters of the current controller have to be tuned in accordance with the filter impedance $\left(L_{1}+L_{2}\right)$ and the estimated value of the grid impedance $\left(L_{\text {grid }}\right)$. In this case, the stability of the controllers depends upon the grid impedance value. If the variation is mainly inductive, then the bandwidth of the controller decreases. In order to alleviate this problem, the gain scheduling method is used to adjust the current controller gain, as presented in Fig. 6. By selecting a proper cut-off frequency for the controller within the limits permitted by the system bandwidth, the resonance can be attenuated. This method guarantees the stability of the system by reselecting the controller gain when the resonance frequency approaches the cut-off frequency of the controller after estimating the grid impedance.

$$
\begin{aligned}
K_{P} & =\left(\omega_{c c}-\Delta \omega_{c c}\right) \cdot L_{T} \\
K_{I} & =\left(\omega_{c c}-\Delta \omega_{c c}\right) \cdot R
\end{aligned}
$$

\section{Simulation}

In order to verify the validity of the proposed algorithm, a simulation was performed using PSIM. The simulation
TABLE I

THE RATED CONDITIONS OF THE SIMULATION

\begin{tabular}{|c|c|}
\hline Rated output power & $1.5 \mathrm{~kW}$ \\
Rated output current & $6.5 \mathrm{Arms}$ \\
Grid voltage & $220 \mathrm{Vrms}, 60 \mathrm{~Hz}$ \\
Switching frequency & $5 \mathrm{kHz}$ \\
\hline
\end{tabular}

was carried out under the conditions listed in Table I. The parameters of the LCL-filter were designed according to the filter design process from Section 2, as shown in Table II.

Fig. 7 shows the variations of the active and reactive power needed to get the voltage and current values from the different operating points when estimating the grid impedance. The amount of power variation is determined to be $16 \%$ of the average power. This makes the grid-connected inverter work at two different operating points by using the PQ variations output through the grid side. Fig. 8 shows the $d q$-axis current variance based on the amount of the power variation of the inverter output. It shows that the $d q$-axis elements change according to the variations in the amount of active power and reactive power.

By obtaining this voltage, the current value changed by the variation of the active and reactive power, it was possible to estimate the grid impedance according to (11). The results of the estimation of the grid impedance obtained by connecting a $1 \Omega$ resistance element to the grid and a $4 \mathrm{mH}$ inductance element are almost the same. In the case where the grid impedance is $3 \mathrm{mH}$ and the controller is working stably, when changing the inductance changes to $4 \mathrm{mH}$, a resonance phenomenon occurs, as shown in Fig. 10(b), due to the change in the resonance frequency. At this time, the proposed method observes the resonant frequency by estimating the grid impedance. This guarantees the stability of the system by changing the current controller gain to be in the stable range, and the resonant phenomenon can be controlled when the resonant frequency approaches the cut-off frequency of the controller. Fig. 10(c) shows the waveform after the gain scheduling. It shows that the resonance, which occurred due to the change in the grid inductance, is reduced. 
TABLE II

THE LCL FILTER PARAMETERS

\begin{tabular}{|c|c|}
\hline $\mathrm{L}_{1}$ & $3.5 \mathrm{mH}$ \\
$\mathrm{L}_{2}$ & $2.5 \mathrm{mH}$ \\
$\mathrm{C}_{\mathrm{f}}$ & $10 \mathrm{uF}$ \\
\hline
\end{tabular}

\section{EXPERIMENTAL RESULTS}

Fig. 11 shows the configuration of the experimental setup. The experiment was performed based on $1.5 \mathrm{~kW}$ experimental equipment. The experiment conditions are performed under the same conditions as the simulation. The LCL-filter parameters were also experimented upon under the same conditions as the simulation. The experimental power conversion equipment is composed of a converter and an inverter, switching at $5 \mathrm{kHz}$. The DC power is connected to the inverter by boosting the voltage through a converter and connected to the grid through an LCL-filter. Fig. 12 shows the estimated grid impedance when a connecting inductor of $3 \mathrm{mH}$ in on the grid side. It shows that the actual inductance and the estimated values are almost the same. In the case of the resistance element, it is estimated to as be almost $0.15 \Omega$. It shows the case where the initial inductance amount on the grid side is set up as to $3 \mathrm{mH}$; and the controller is stable, as shown in the Fig. 13(a). When the grid side impedance increases to $4 \mathrm{mH}$, the resonance frequency approaches the cut-off frequency of the current controller and generates a resonance phenomenon in the frequency band of about 1.1kHz. Fig. 13(b) shows the generated resonance phenomenon due to the resonance frequency. By using the proposed gain scheduling method, when setting up the cut-off frequency of the current controller to the safe resonance frequency range, the resonance phenomenon, due to the change in the grid impedance, is compensated for, as shown in Fig. 13(c). Comparing Fig. 13(a) and Fig. 13(b), the reduced pulsation of the resonance frequency band occurred from the change in the grid impedance reduced by the proposed method. Since the impedance of the grid cannot be changed deliberately, it includes extra impedance between the output of the inverter and the grid. By changing this extra impedance, the proposed method is verified under different impedances.

\section{CONCLUSION}

This paper proposed a method to improve the stability of grid-connected systems with an LCL-filter by using a gain scheduling method through grid impedance estimation. The proposed method guarantees stability, even if the system is unstable due to changes in the grid impedance. The resonant phenomenon caused by changes in the grid impedance is well compensated and the stability of the system is improved by using the gain scheduling method through grid impedance estimation. The validity of the proposed method was demonstrated by simulation and experimental results.

\section{ACKNOWLEDGMENT}

This work was supported by the National Research Foundation of Korea (NRF) grant funded by the Korea Government (MEST) (No. 2010-0011933).

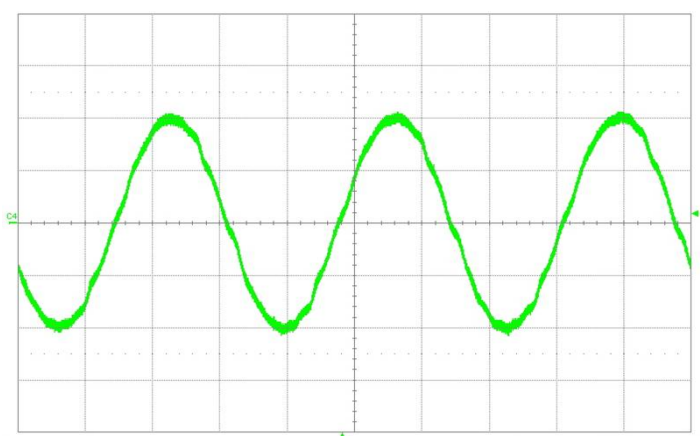

(a) Grid inductance $=3 \mathrm{mH}, \mathrm{K}_{\mathrm{p}}=36, \mathrm{~K}_{\mathrm{I}}=350$. (x-axis: $5 \mathrm{~s} / \mathrm{div}$. y-axis: $5 \mathrm{~A} / \mathrm{div}$ )

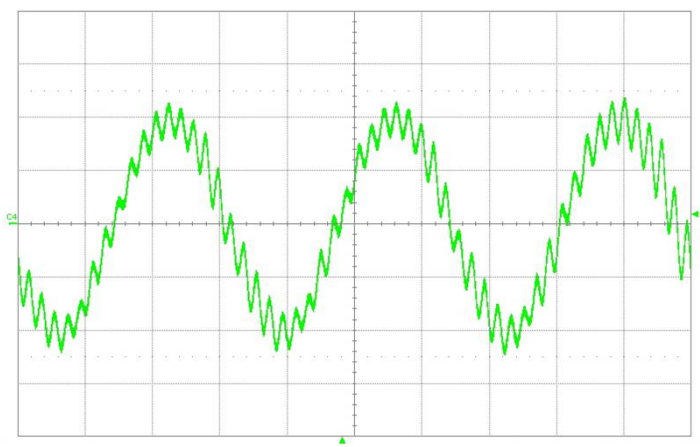

(b) Grid inductance $=4 \mathrm{mH}, \mathrm{K}_{\mathrm{p}}=36, \mathrm{~K}_{\mathrm{I}}=350$. (x-axis: $5 \mathrm{~s} /$ div., y-axis: $5 \mathrm{~A} / \mathrm{div})$

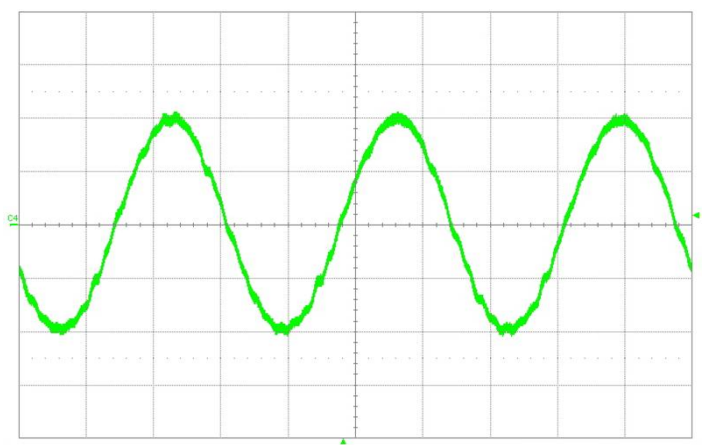

(c) Grid inductance $=4 \mathrm{mH}, \mathrm{K}_{\mathrm{p}}=24, \mathrm{~K}_{\mathrm{I}}=270$. (x-axis: $5 \mathrm{~s} /$ div., y-axis: $5 \mathrm{~A} / \mathrm{div}$ )

Fig. 13. The output current waveforms of the grid-connected inverter.

\section{REFERENCES}

[1] F. Blaabjerg Z. Chen, and S. B. Kjaer, "Power electronics as efficient interface in dispersed power generation systems," IEEE Trans. Power Electron., Vol. 19, No. 5, pp. 1184-1194, Sep. 2004.

[2] J. H. Kim, Y. C. Jung, C. W. Lee, T. W. Lee, and C. Y. Won, "Power loss analysis of interleaved soft switching boost converter for single-phase PV-PCS," Journal of Power Electronics, Vol. 10, No. 4, pp. 335-341, Jun. 2010.

[3] K. Park and K. B. Lee, "Hardware simulator development for a 3parallel grid-connected PMSG wind power system," Journal of Power Electronics, Vol. 10, No. 5, pp. 555-562, Sep. 2010.

[4] IEEE Standard 929-2000 : IEEE Recommended practice for utility interface of photovoltaic (PV) systems.

[5] IEEE Standard 1547-2003 : IEEE Standard for interconnecting distributed resources with electric power systems.

[6] S. Lee, J. Kim, and H. Cha, "Design and implementation of photovoltaic power conditioning system using a current-based maximum power point tracking," Journal of Electrical Engineering \& Technology, Vol. 5, No. 1, pp. 129-139, Mar. 2010.

[7] Y. J. Ko and K. B. Lee, "Fault diagnosis of a voltage-fed PWM inverter for a three-parallel power conversion system in a wind turbine," Journal of Power Electronics, Vol. 10, No. 6, pp. 686-693, Nov. 2010. 
[8] M. P. Kazmierkowski, R. Krishnan, and F. Blaabjerg, Control in Power Electronics, New York Academic, 2002.

[9] M. Liserre, F. Blaabjerg. and S. Hansen, "Design and control of an LCLfilter-based three-phase active rectifier," IEEE Trans. Ind. Appl., Vol 41 No. 5, pp. 1284-1285, Oct. 2005.

[10] M. Liserre, F. Blaabjerg, and R. Teodorescu, "Grid impedance estimation via excitation of LCL-filter resonance," IEEE Trans. Ind. Appl., Vol. 43, No. 5, pp. 1401-1407, Sep./Oct. 2007.

[11] H. K. Jeong, K. B. Lee, S. Choi, and W. Choi, "Performance improvement of LCL-filter based grid connected-inverters using PQR power transformations," IEEE Trans. Power Electron., Vol. 25, No. 5, pp. 13201330, May 2010.

[12] M. Liserre, R. Teodorescu, and F. Blaabjerg "Stability improvements of an LCL-filter based three-phase active rectifier," IEEE PESC'02, pp. 1195-1201, Jun. 2002.

[13] V. Blasko and V. Kaura, "A novel control to actively damp resonance in input lc filter of three-phase voltage source converter," IEEE Trans. Ind. Appl., Vol. 33, No. 2, pp. 542-550, Mar./Apr. 1997.

[14] P. K. Dahono, "A control method for DC-DC converter that has an LCL output filter based on new virtual capacitor and resistor concept," IEEE PESC'04, pp. 36-42, Jun. 2004.

[15] M. Liserre, R. Teodorescu, and F. Blaabjerg, "Stability of grid-connected PV inverters with large grid impedance variation," IEEE PESC'04, pp. 4773-4779, Jun. 2004.

[16] M. Ciobotaru, R. Teodorescu, P. Rodriguez, A. Timbus, and F. Blaabjerg, "Online grid impedance estimation for single-phase grid connected systems using PQ variations," IEEE PESC'07, pp. 2306-2312, Sep./Oct. 2007.
[17] D. Georgakis, S. Papathanassiou, N. Hatziargyriou, A. Engler, and C. Hardt, "Operation of a prototype microgrid system based on microsources quipped with fast-acting power electronics interfaces," IEEE PESC'04, pp. 2521- 2526, Jun. 2004.

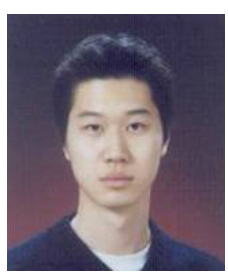

Dae-Keun Choi was born in Seoul, Korea, in 1980. He received his B.S. and M.S. in Electronic Engineering from Ajou University, Suwon, Korea, in 2009 and in 2011, respectively. He is currently working toward his $\mathrm{Ph} . \mathrm{D}$. at Ajou University. His current research interests include power conversion and grid-connected systems.

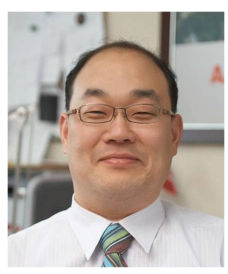

Kyo-Beum Lee was born in Seoul, Korea, in 1972. He received his B.S. and M.S. in Electrical and Electronic Engineering from Ajou University, Suwon, Korea, in 1997 and 1999, respectively. He received his Ph.D. in Electrical Engineering from Korea University, Seoul, Korea, in 2003. From 2003 to 2006, he was with the Institute of Energy Technology, Aalborg University, Aalborg, Denmark. From 2006 to 2007, he was with the Division of Electronics and Information Engineering, Chonbuk National University, Jeonju, Korea. In 2007 he joined the School of Electrical and Computer Engineering, Ajou University, Suwon, Korea. He is an Associated Editor of the IEEE Transactions on Power Electronics and the Journal of Power Electronics. His current research interests include electric machine drives and renewable power generation. 